\title{
Outcomes research in chronic viral hepatitis C: Effects of interferon therapy
}

\author{
Herbert L Bonkovsky MD ${ }^{1-3}$, J Michael Woolley PhD ${ }^{4}$
}

HL Bonkovsky, JM Woolley. Outcomes research in chronic viral hepatitis C: Effects of interferon therapy. Can J Gastroenterol 2000;14(Suppl B):21B-29B. Although chronic hepatitis $\mathrm{C}(\mathrm{CHC})$ is often mild and asymptomatic, it may lead to decompensated hepatic cirrhosis and death. $\mathrm{CHC}$ is now the single most important indication for liver transplantation in North America. $\mathrm{CHC}$ is also an important cause of morbidity. Recent work is reviewed and shows that the health-related quality of life (HRQOL) of patients with CHC is markedly reduced compared with that of age- and sex-matched controls. For as yet unknown reasons, this reduction is more severe in $\mathrm{CHC}$ patients than in those with chronic hepatitis B. Successful therapy of $\mathrm{CHC}$ with type 1 interferons (IFNs) leads to substantial improvement - to nearly normal levels - in patients' HRQOL. In addition, IFN or IFN plus ribavirin therapy for $\mathrm{CHC}$ is highly cost effective, despite its limited long term efficacy; estimates of the costs to gain one year of quality-adjusted life range from no cost (that is, therapy is cost saving) to US $\$ 11,400$ (for those most difficult to cure). Thus, despite the limited effectiveness of current therapies for $\mathrm{CHC}$, they are fully justified based on their beneficial effects on patients' HRQOL and their cost effectiveness.

Key Words: Chronic hepatitis C; Cost effectiveness; Health-related quality of life; Hepatitis; Interferon; Relapse; Treatment response; Virology

\section{Résultats du traitement à l'interféron chez les patients atteints d'hépatite $\mathrm{C}$ chronique}

RÉSUMÉ : Même si l'hépatite C chronique (HCC) est souvent une maladie bénigne et asymptomatique, elle peut aussi entraîner une cirrhose hépatique décompensée et la mort. L'HCC constitue actuellement la principale indication des transplantations du foie en Amérique du Nord et elle est également une importante cause de morbidité. Des travaux récents ont été passés en revue et ils révèlent que la qualité de vie liée à la santé (QVLS) des patients atteints d'HCC est considérablement réduite par rapport à celle de témoins appariés suivant l'âge et le sexe. D'ailleurs, pour une raison encore inconnue, cette réduction est plus marquée chez les patients atteints d'HCC que chez ceux qui souffrent d'hépatite B. Toutefois, le traitement de l'HCC à l'interféron de type I (IFN), couronné de succès, permet une amélioration sensible de la QVLS, qui s'approche de la normale. En outre, le traitement à l'IFN ou à l'IFN associé à la ribavine chez les patients atteints d'HCC offre un très bon rapport coût-efficacité, malgré son efficacité limitée dans le temps; les estimations de coût pour gagner une année de meilleure qualité varient de zéro (le traitement entraîne une réduction de coûts) à 11400 \$US (pour les cas les plus difficiles à traiter). Aussi les traitements actuels de l'HCC, malgré leur efficacité limitée, sont-ils pleinement justifiés si l'on tient compte de l'amélioration de la QVLS et de leur rapport coût-efficacité.
$\mathrm{C}$ hronic hepatitis $\mathrm{C}(\mathrm{CHC})$ is a major cause of liver disease worldwide. The acute infection is thought to be milder than that of hepatitis A or B, but those who are infected by hepatitis $\mathrm{C}$ are more likely to develop chronic hepatitis (1). Currently, an estimated $1.8 \%$ of the American population (about four million people) have $\mathrm{CHC}$, and it is thought to be the leading cause of orthotopic liver transplantation in the United States and other western countries (2).

Although the long term consequences of hepatitis Chave become better understood, it is only recently that researchers - including the present authors - have begun to assess the effects of the disease on patient functional status and well-

This mini-review includes material from a presentation made at the World Congress of Gastroenterology in Vienna, Austria, September 6 to 11,1998 Departments of ${ }^{1}$ Medicine, and ${ }^{2}$ Biochemistry 8 Molecular Biology, University of Massachusetts Medical School, and ${ }^{3}$ The Liver, Biliary,

Pancreatic Center of University of Massachusetts Memorial Health Care, Worcester, Massachusetts, USA; ${ }^{4}$ Department of Health

Economics, Amgen, Inc, Thousand Oaks, California, USA

Correspondence and reprints: Dr Herbert L Bonkovsky, University of Massachusetts Medical School, Room S6-737, 55 Lake Avenue North,

Worcester, Massachusetts 01655, USA. Telephone 508-856-3068, fax 508-856-3981

Received for publication March 12, 1999. Accepted March 18, 1999 
being. It had been believed that hepatitis $\mathrm{C}$ was relatively benign, especially before development of hepatic cirrhosis. However, as will be discussed, CHC, even in patients without cirrhosis, has a significant adverse effect on patients' health-related quality of life (HRQOL).

\section{HEALTH-RELATED QUALITY OF LIFE}

HRQOL has been defined as "patients' appraisals of their current level of functioning and satisfaction with it com pared to what they perceive to be ideal" (3). This definition incorporates "the impairments, functional states, perceptions, and social opportunities that are influenced by disease, injury, treatment, or policy" (4).

While the measurement of HRQOL should be objective, the concept of HRQOL by definition is subjective. It depends upon patients' feelings about theit wellness or illness and the import they attach to these perceptions as they affect the patients' lives, and patients' interactions with their families and society at large. The evaluation of a patient's HRQOL must be based on assessments performed by each patient. Patients are in the best position to assess their own HRQOL, and some researchers argue that patient assessments are in many ways superior to assessments performed by others (5). The Division of Drug Marketing, Advertising and Communications at the United States Food and Drug Administration recognizes this, stating in its draft principles for the review of pharmacoeconomic promotions that "QOL claims should be based on the patient's perspective. Scales to measure QOL generally require patient input in both their development and their application" (6).

Methods for assessing HRQOL: A variety of tools have been developed to assess HRQOL. These tools typically are questionnaires, in which patients respond to a series of items that are then aggregated to form scales. Each scale should be a separate conceptual construct measuring a unique HRQOL domain. It is important that HRQOL instruments incorporate relevant domains and that they be reliable, valid and sensitive.
HRQOL instruments are sometimes divided into two types: generic instruments, which assess HRQOL domains relevant across a variety of diseases and/or populations, and disease-targeted (sometimes called disease-specific) instruments, which assess HRQOL domains focused on the disease of interest. Disease-targeted instruments are designed to be more sensitive than generic instruments but are of limited use (due to their limited application) in making comparisons 6 across diseases, populations or both. A sufficiently sensitive generic instrument, if available, can provide the best assessment tool, measuring a full range of HRQOL domains and providing a standard for comparisons among diseases.

Among the most well known and commonly used generic HRQOL instruments are the Sickness Impact Profile (SIP) and the Short Form-36 (SF-36). Both assess a wide range of HRQOL domains from physical functioning to psychosocial well-being, and both have been used to assess the HRQOL in patients with hepatitis C.

The SIP was first developed by Bergner et al (7) and others (8-11) at the University of Washington in the 1970s. The SIP consists of 136 items that can be combined to form 12 scale scores, as well as a total score (Table 1). Patients review each item in the SIP and endorse those items that describe them on that day and relate to their health. Scores for each scale, as well as for the total, range from 0 to 100 , with higher scores connoting poorer HRQOL. The SIP can be either self- or interviewer-administered, and requires about 20 to 30 mins to complete.

The SIP has been applied to study several diseases of varying severity (12-15). While its psychometric properties are good and its overall validity reasonable, many of the items in the SIP measure extremely low levels of function; thus, the SIP may be more useful to assess HRQOL in those who are very ill. Because this instrument may lack the sensitivity to detect meaningful changes in HRQOL, particularly for patients with hepatitis $\mathrm{C}$ without cirrhosis, it is important to validate the SIP in patients with hepatitis $\mathrm{C}$ before its use in clinical trials.

\section{TABLE 1}

Sickness Impact Profile

\begin{tabular}{|c|c|c|c|}
\hline Category & \# of items & Sample item & High scores (poorer HRQOL) \\
\hline Ambulation & 12 & I walk more slowly & Limited or unable to walk \\
\hline Body care and movement & 23 & I change position frequently & Difficult or impossible to dress, bathe or gef around \\
\hline Mobility & 10 & I am not going into town & Remain confined to home or room \\
\hline Home management & 10 & $\begin{array}{l}\text { I am not doing any of the clothes washing that } \\
\text { I usually do }\end{array}$ & Unable to do some or all work around home \\
\hline Sleep and rest & 7 & I sit during much of the day & Lying down or sleeping most of day \\
\hline Eating & 9 & I am eating much less than usual & Unable to eat or require special diet \\
\hline Work & 9 & I am not working at all & Limited orunable to work \\
\hline Recreation and pastimes & 8 & I am doing fewer community activities & Reduced recreation or hobbies \\
\hline Communication & 9 & I don't write except to sign my name & Difficult or impossible to speak or write \\
\hline Social interaction & 20 & I am going out less to visit people & Reduced activities with family or friends \\
\hline Alertness behaviour & 10 & $\begin{array}{l}\text { I do not keep my attention on any activity } \\
\text { for long }\end{array}$ & Difficulty with concentration or memory \\
\hline Emotional behaviour & 9 & I act nervous or restless & Irritable, nervous or depressed \\
\hline
\end{tabular}

Scores range from 0 to 100, with higher scores connoting poorer health-related quality of life (HRQOL) 
TABLE 2

Short Form-36

\begin{tabular}{|c|c|c|c|}
\hline \multirow[b]{2}{*}{ Concepts } & \multirow{2}{*}{$\begin{array}{c}\# \\
\text { of items }\end{array}$} & \multicolumn{2}{|l|}{ Meaning of scores } \\
\hline & & Low (poorer HRQOL) & High (better HRQOL) \\
\hline Physical functioning & 10 & $\begin{array}{l}\text { Limited a lot in performing all physical activities } \\
\text { including bathing or dressing }\end{array}$ & $\begin{array}{l}\text { Performs all types of physical activities including the } \\
\text { most vigorous without limitations due to health }\end{array}$ \\
\hline $\begin{array}{l}\text { Role limitations due to } \\
\text { physical problems }\end{array}$ & 4 & $\begin{array}{l}\text { Problems with work or other daily activities } \\
\text { as a result of physical health }\end{array}$ & $\begin{array}{l}\text { No problems with work or other daily activities as result } \\
\text { of physical health in the past four weeks }\end{array}$ \\
\hline Bodily pain & 2 & Very severe and extremely limiting $p$ & No pain or limitations due to pain in the past four weeks \\
\hline General health & 5 & $\begin{array}{l}\text { Believes personal } \\
\text { to get worse }\end{array}$ & Believes personal health is excellent \\
\hline Vitality & 4 & Feels tired and & $\begin{array}{l}\text { Feels full of pep and energy all of the time in the past } \\
\text { four weeks }\end{array}$ \\
\hline Social functioning & 2 & $\begin{array}{l}\text { Extreme and frequent interference with normal } \\
\text { social activities due to physical and emotional } \\
\text { problems }\end{array}$ & $\begin{array}{l}\text { Performs normal social activities without interference } \\
\text { due to physical or emotional problems in the past } \\
\text { four weeks }\end{array}$ \\
\hline $\begin{array}{l}\text { Role limitations due to } \\
\text { emotional problems }\end{array}$ & 3 & $\begin{array}{l}\text { Problems with work or other daily activities } \\
\text { as a result of emotional problems }\end{array}$ & $\begin{array}{l}\text { No problems with work or other daily activities as a } \\
\text { result of emotional problems in the past four weeks }\end{array}$ \\
\hline Mental health & 5 & $\begin{array}{l}\text { Feelings of nervousness and depression all } \\
\text { of the time }\end{array}$ & $\begin{array}{l}\text { Feels peaceful, happy and calm all of the time in the } \\
\text { past four weeks }\end{array}$ \\
\hline
\end{tabular}

Scores range from 0 to 100, with lower scores connoting poorer health-related quality of life (HRQOL)

The SF-36 was developed from a larger instrument used in the Medical Outcomes Study (MOS) conducted in the 1980s (16). Items in the MOS were based on instruments that had been in use for over 20 years and had proven useful during the RAND Health Insurance Experiment (17). To form the SF-36, 36 items were selected from the 149-item MOS Functioning and Well-Being Profile. These 36 items, which were selected to represent the most important health concepts in the MOS, can be combined to form eight HRQOL scales ranging from physical function to mental health (Table 2).

The SF-36 has been used in a variety of diseases and populations, and has generally performed well (18-20). It has been shown to be reliable and valid using different methods of administration and across a number of diseases. The SF-36 has been validated in patients with hepatitis $\mathrm{C}$ (21).

\section{SUMMARY OF PUBLISHED RESULTS ON HRQOL IN CHRONIC VIRAL HEPATITIS}

CHC has an adverse impact on HRQOL: At the time of submission of this paper, HRQOL had been evaluated and reported for $\mathrm{CHC}$ patients who participated in five studies on therapy with type 1 interferons (IFNs) (Table 3) (22-26). A total of 1069 subjects completed at least one instrument to assess HRQOL (Table 3). Figure 1 summarizes these results in graphical form. In every study, the HRQOL at baseline was lower than that of controls. In the largest study (26), the decreases experienced by men versus women with $\mathrm{CHC}$ were of similar magnitude and of high clinical and statistical significance. Decreases were more pronounced in domains of the SF-36 that principally measure perceptions of physical, rather than mental or emotional, well-being. Furthermore, the decreases were sizable - of a magnitude considered to be clinically and socially important $(18)$. In two studies $(23,26)$, $\mathrm{CHC}$ patients with and without cirrhosis were compared, and had similar and significant decreases in HRQOL. If patients with more advanced decompensated cirrhosis were studied, it is expected that the reduction in HRQOL would be greater.

Although there may be concern that a recent diagnosis of hepatitis C could produce a misleadingly low HRQOL score, Bonkovsky and Woolley (26) found that the HRQOL scores were stable over time and that patients who were more recently diagnosed with $\mathrm{CHC}$ had higher HRQOL than those diagnosed more remotely. Furthermore, the majority of patients included in that study had been aware of their diagnosis for some time. Therefore, reductions in HRQOL in CHC do not appear to be due to a transient 'shock effect' of being diagnosed.

Women in that study (26) reported lower HRQOL scores than men, a finding also noted in controls and patients with other diseases. Because a greater percentage of $\mathrm{CHC}$ patients in this study were men (men comprised $73 \%$ of study participants but only $47 \%$ of controls), comparisons that were not sex-adjusted with controls were expected to be biased (ie, unadjusted comparisons would show smaller differences than sex-adjusted comparisons). This proved to be the case, as age- and sex-adjusted differences were even more pronounced than those without such adjustments.

Bonkovsky and Woolley (26) found no detectable effect on HRQOL of several other clinical or laboratory features at baseline, including viral genotype, serum viral titre or liver chemistries (serum albumin, alkaline phosphatase, alanine aminotransferase [ALT], aspartate aminotransferase, total bilirubin or prothrombin time). Similarly, Foster et al (25) found no correlation between HRQOL scores and levels of serum ALT. However, patients were excluded from studies if they showed any evidence of hepatic decompensation $(26,27)$ or if they had cirrhosis $(25)$.

All of the reported studies thus far have been performed 
TABLE 3

Summary of published studies on health-related quality of life (HRQOL) in patients with chronic hepatitis $\mathrm{C}(\mathrm{CHC})$

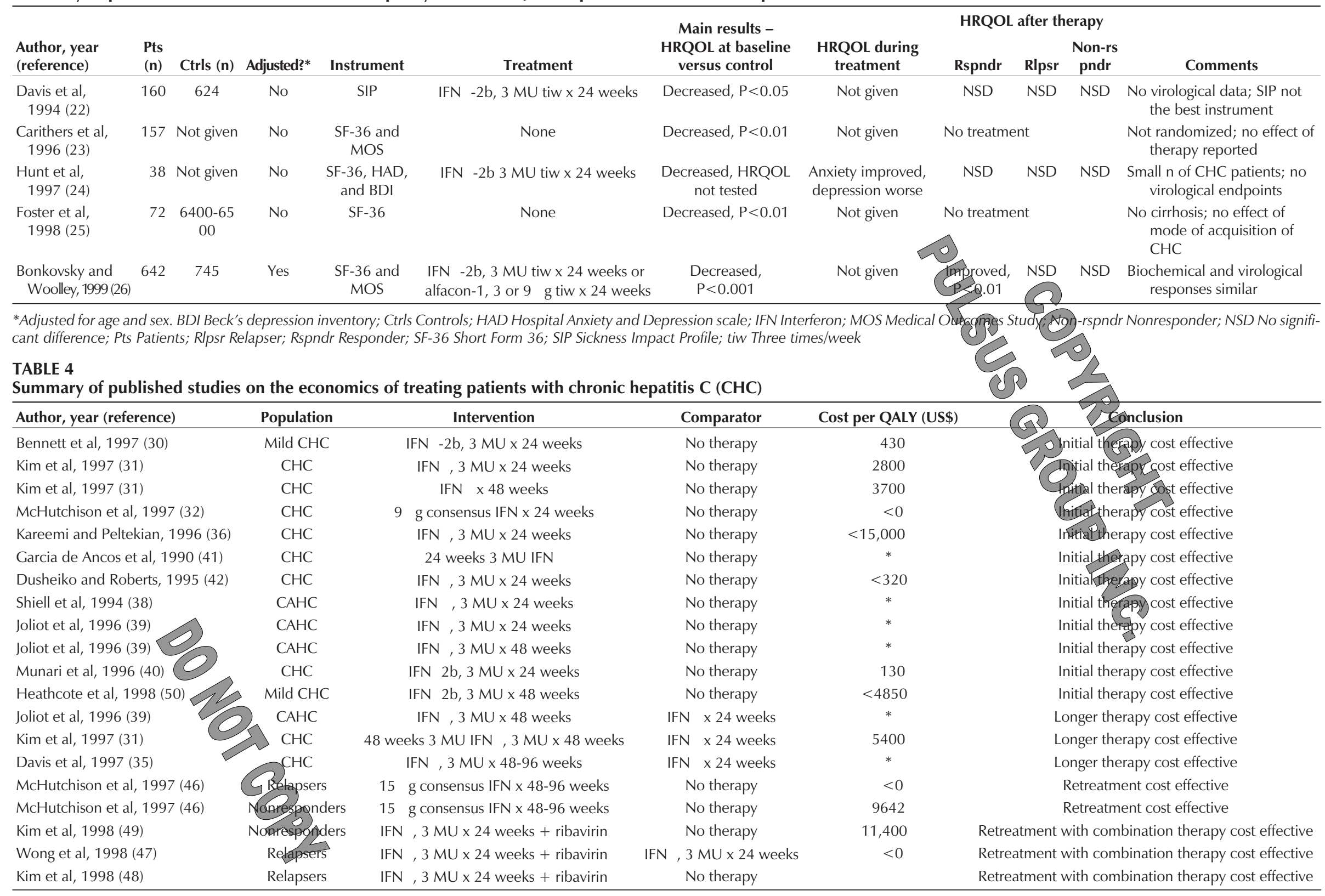



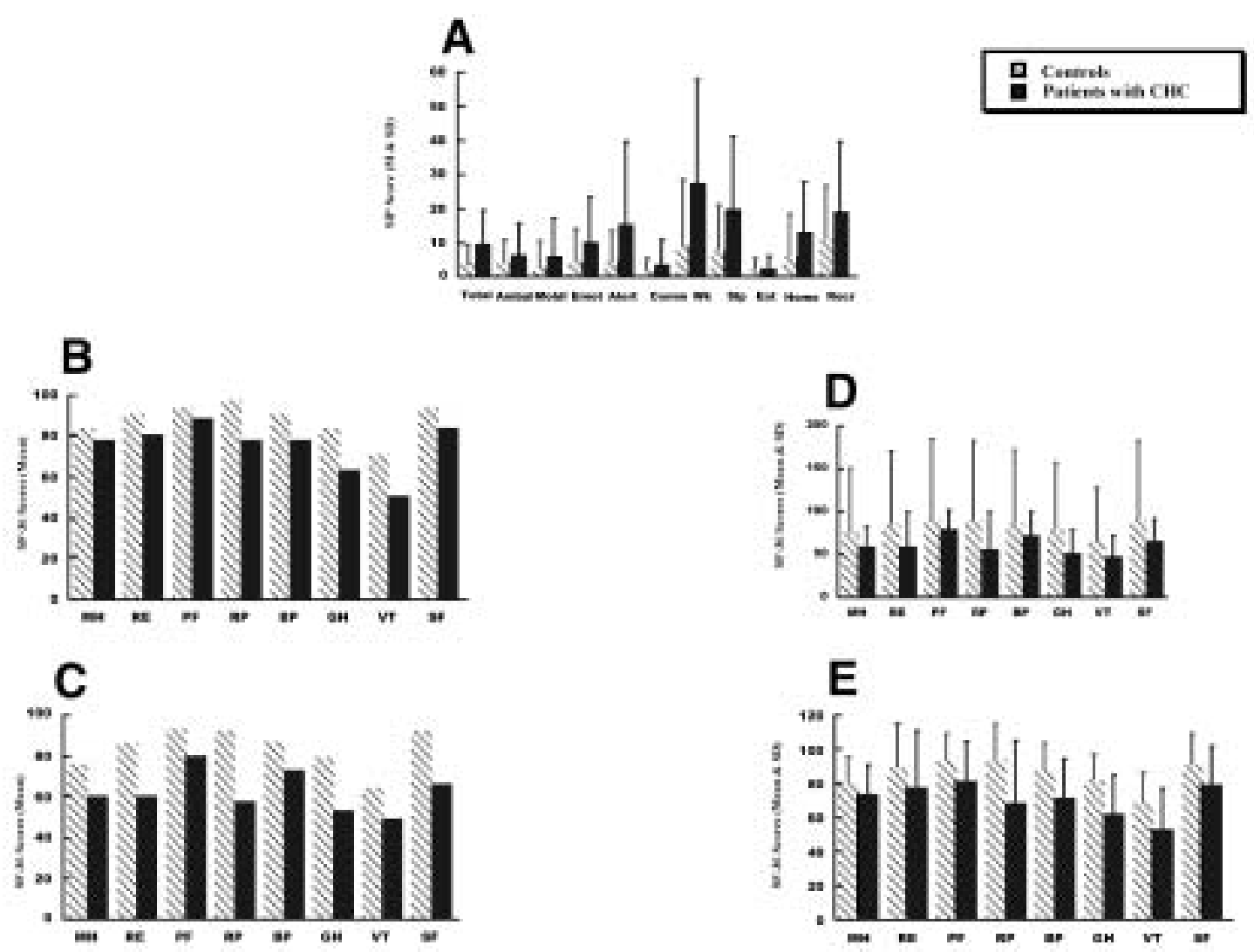

Figure 1) Health-related quality of life in patients with chronic hepatitis $\mathrm{C}$ (CHC) at baseline compared with that of controls. A Summary of results of Davis et al (22) comparing 160 CHC patients with 624 controls (not sex-or age-adjusted). The Sickness Impact Profile (SIP) - in which higher numerical scores indicate a worse status - was used. Results are mean $(\mathrm{m})$ and SDs. Patients with CHC were significantly worse than controls $(P<0.05)$ for all domains except eating (Eat). B Results of Carithers et al (23), comparing 157 CHC patients with general population data ( $n$ not stated; not sex- or ageadjusted). The Short-Form 36 (SF-36), in which higher numerical scores indicate better status, was used. Mean values are shown (SDs were not given). All differences were significant $(P<0.01)$. C Results of Hunt et al (24), comparing $38 \mathrm{CHC}$ patients with the general American population aged 35 to 44 years ( $n$ not stated; not sex-or age-adjusted). The SF-36 was used. Results shown are median values. P values were not given. Note that, for all eight domains, the median scores were lower for patients with CHC than for controls. D Results of Foster and co-workers (25), comparing $72 \mathrm{CHC}$ patients with 6400 to 6500 controls (not age-or sex-adjusted). The SF-36 was used. Results are means and SDs. All differences were significant (P<0.01). E Summary of results from Bonkovsky and Woolley (26), comparing 642 patients with CHC to 745 controls (age-and sex-adjusted). The SF-36 was used. Results are means and SDs; all differences were significant $(P<0.001)$. Alert Alertness; Ambul Ambulation; BP Bodily pain; Comm Communication; Emot Emotional; GH General health; Home Home functioning; MH Mental health; Mobil Mobility; PF Physical functioning; RE Role emotional; Recr Recreation; RP Role physical; SF Social functioning; Total SIP; Slp Sleeping; VT Vitality; Wk Work

in secondary or tertiary teaching centres on patients who were participating in therapeutic trials of IFN. Therefore, these results may not reflect the status of all persons with active hepatitis $\mathrm{C}$ virus (HCV) infection. Perhaps there was referral bias, and perhaps patients who enrolled in these trials were more symptomatic, more anxious and/or more depressed by their knowledge of viral infection than the population of infected persons. However, some data do not support this hypothesis. For example, Foster et al (25) compared the HRQOL of patients diagnosed with HCV after presenting with symptoms with the HRQOL of patients diagnosed on routine screening or periodic check-ups. These researchers found no differences in HRQOL. In addition, most of these patients were referred by their local general practitioners, leading Foster and associates (25) to conclude that the reductions they observed were representative of the general population of $\mathrm{CHC}$ subjects. Resolving possible referral bias would require a very large and expensive population-based study of HRQOL carried out in subjects who were unaware of results of hepatic inflammation or $\mathrm{HCV}$ infection tests.

In summary, all of the larger studies (each involving more than 70 patients) thus far reported have concluded that $\mathrm{HRQOL}$ is significantly reduced in $\mathrm{CHC}$ patients, regardless of the severity of inflammation, stage of disease, or viral genotype or loads (Table 3, Figure 1).

HRQOL is reduced less in chronic hepatitis $B$ than in CHC: To the authors' knowledge, there is only one study of HRQOL in patients with chronic hepatitis B (25). It was carried out in 30 noncirrhotic patients with chronic hepatitis $B$ 


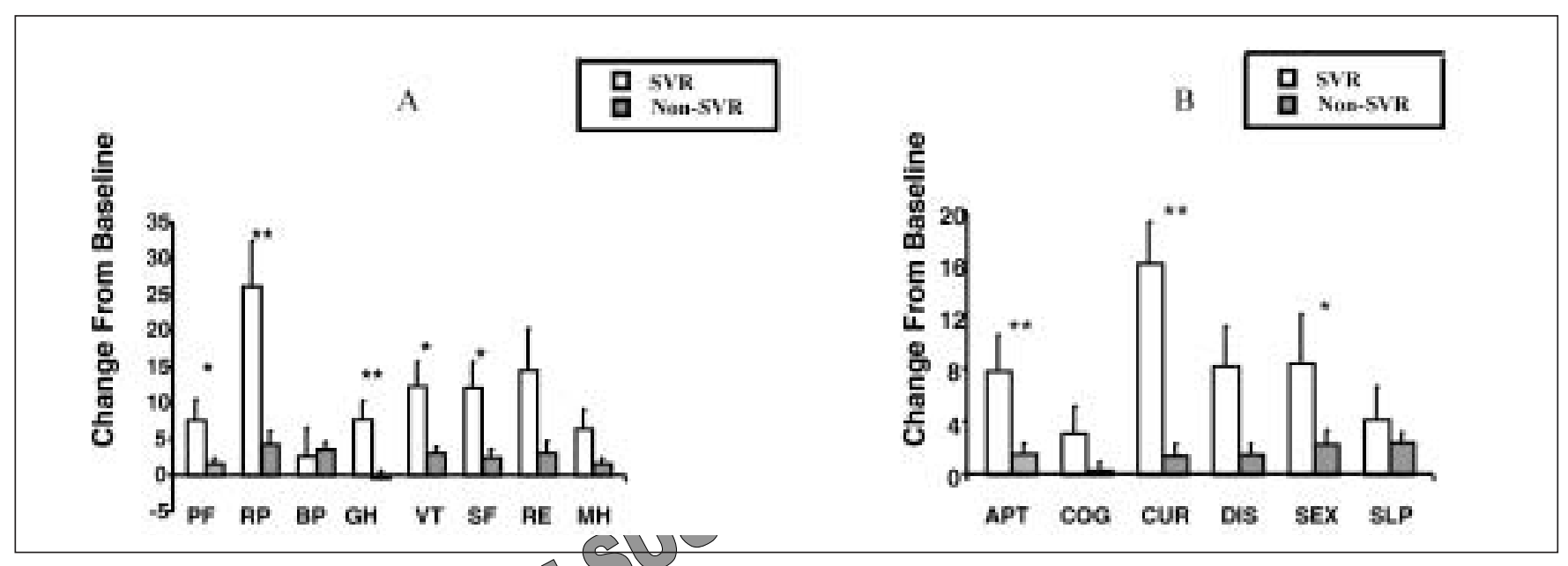

Figure 2) Improvements in patients' health-related quality of life ( $\mathrm{HRQOL}$ ) by virological response status in patients with chronic hepatitis C. A Short Form-36 scale; B Medical Outcomes Study scale. Results show mean + SD improvement from baseline in HRQOL scores. Results for sustained virological responders $(n=41)$ are shown as open columns and for nonsustained virological responders $(n=396)$ as shaded columns. $* P<0.05, * * P<0.01$ comparing sustained with nonsustained responders. APT Appetite; BP Bodily pain; COG Cognitive function; CUR Perception of current health; DIS Feeling of health distress; GH General health; MH Mental health; PF Physical functioning; RE Role emotional; RP Role physical; SEX Sexual functioning; SF Social functioning; SLP Sleep quality; SVR Sustained virological response; VT Vitality. Data from reference 26

without hepatocellular carcinoma or other significant disorders. In striking contrast to the results of $\mathrm{CHC}$ patients, SF36 scores for these chronic hepatitis B patients were much closer to those for controls. Only for the mental health and general health perception scales were differences between controls and patients with chronic hepatitis B significant $(\mathrm{P}<0.01)$. SF-36 scores for $\mathrm{CHC}$ patients were lower than those for chronic hepatitis $\mathrm{B}$ patients in every scale, and significantly worse for three scales: social functioning, role limitation physical, and vitality. Thus, chronic HCV infection produces more severe systemic symptoms and feelings of illness in patients than chronic HBV infection. The reasons for this are not clear.

Successful treatment of CHC improves HRQOL: The effects of IFN therapy on HRQOL in CHC have been assessed in three trials $(22,24,26)$. In the first study $(22)$, the SIP was used to evaluate HRQOL, whereas in the other two $(24,26)$, the SF-36 was the principal instrument used. Only in the third (26) was response to therapy monitored by a sensitive test for viral RNA (SuperQuant; NGI, Culver City, California), as well as by improvements in serum ALT levels.

In addition, the first two trials were relatively small $(n=160$ and $n=38)$ compared with the third $(n=642)$. Because the frequency of sustained virological responses (SVR) is low in CHC patients treated with 'standard' doses of IFN (3 MU IFN -2b or 9 g alfacon-1 thrice weekly for 24 weeks), the number of responding patients in small trials is likely too low to generate robust results (ie, the possibility of a type II error is high).

In the studies of Davis et al (22) and Hunt et al (24), no significant differences in HRQOL were observed when biochemical responders were compared with biochemical nonresponders. (A biochemical response is defined as a sustained return of serum ALT into the normal range during and after IFN therapy.) However, in the study of Bonkovsky and
Woolley (26), patients with SVR or sustained biochemical responses (SBR) experienced HRQOL improvements in all eight SF-36 scales (seven were statistically significant) and exceeded those for patients without SVR in seven of the scales (five were statistically significant) (Figure 2). The degree of improvement achieved in patients with SVR was substantial; scores 24 weeks after the end of successful treatment were not significantly different from those of an age- and sex-adjusted normal control population. The only exception was the general health scale of the SF-36, in which the difference from control at baseline was -16 , while at the end of post-treatment follow-up it was -9.1 (difference from control, $\mathrm{P}<0.05$ ).

Such substantial improvement after successful therapy also suggested to Bonkovsky and Woolley (26) that the reductions in HRQOL observed in patients before treatment were due to the viral infection, rather than to other coexisting factors such as lower socioeconomic or educational status, intravenous or intranasal illicit drug use, or alcohol abuse. In contrast, patients without SVR had smaller, statistically and clinically insignificant improvements in all eight SF-36 scale scores (Figure 2). Those with little or no virological response during IFN therapy did not experience any significant improvement in HRQOL. The improvements in HRQOL among sustained and nonsustained (relapsing) biochemical responders were similar in pattern but not quite as large as those in virological responders.

Further, in that study (26), patients and their physicians were blinded to viral response status when the patients completed the HRQOL questionnaires. However, patients may have been aware of their biochemical response status. Thus, it is possible that patient knowledge of their SBR status, which is highly correlated with SVR status, may have contributed to the reported improvement due to successful therapy. However, patients' knowledge of biochemical response 
status was unlikely to have been a significant factor because the analysis was conducted using patients who were complete and sustained biochemical responders (SBR at the time they completed the end-of-study HRQOL questionnaire, $\mathrm{n}=62)$. Patients with SVR $(\mathrm{n}=30)$ achieved improvements in HRQOL that exceeded those of patients without SVR $(n=32)$ in seven of eight SF-36 scales (three were statistically significant), with an average increase more than three times as great. Thus, viral response status seems to be the most important determinant of HRQOL improvement, and it is unlikely that patients' knowledge of their biochemical responses had a major influence on these results.

In summary, successful treatment of $\mathrm{CHC}$ produces marked improvement in HRQOL that is maintained for at least six months after the end of therapy and likely is sustained permanently, as is virological response (28).

\section{COST EFFECTIVENESS OF TREATMENT}

While both laboratory and HRQOL data show the benefits of therapy for hepatitis $\mathrm{C}$, its cost necessitates the evaluation of the cost effectiveness of treatment. With competing demands for scarce health care resources, the optimal allocation of these resources is critical. Economic analysis is a method whereby such resource allocation decisions can be made rationally, potentially (ideally) allowing them to be used to generate the greatest good for society.

Typically, economic analysis of a therapy considers the cost of obtaining a specified benefit. The most common measures of economic benefits are life-years, which consider the effect of therapy on life expectancy, and quality-adjusted life-years (QALYs), which consider the effects on quality of life and life expectancy in combination. Analyses using either method have the advantage of using a common, readily understood measure of treatment benefits (the cost per QALY or cost per life-year). Comparisons can then be made across diseases and therapies - those with the lowest cost per QALY are considered to be the most cost effective. Allocating health care resources to such therapies is a way of obtaining the greatest benefit for a given amount of money, ie, the lowest cost method for an additional QALY. Some have proposed that a treatment with a cost per QALY of less than US $\$ 50,000$ is cost effective, while a cost per QALY exceeding US $\$ 100,000$ is not cost effective (29).

Hepatitis C treatments can affect outcomes over many years, well beyond the time frame of conventional trials. Thus, analyses of such treatments cannot be based entirely on trial data. Models need to be developed to incorporate trial results into a lifetime perspective on patients with $\mathrm{CHC}$. These models typically describe the possible outcomes (costs, survival and quality of life) of hepatitis $\mathrm{C}$ infection and assess how the outcomes are affected by treatment. A number of researchers have developed such models in order to conduct economic analyses of hepatitis $\mathrm{C}$ therapies (30-49).

Treatment for previously untreated patients: There have been several studies of IFN therapy for previously untreated patients with $\mathrm{CHC}(30-41)$. Bennett et al (30) examined whether treatment of histologically mild $\mathrm{CHC}$ with a six- month course of IFN - $2 \mathrm{~b}$ was cost effective. The authors developed a Markov model of $\mathrm{CHC}$ and presented evidence of both its validity and robustness. Using a SVR rate of $27.3 \%$, the authors found that such therapy, at a cost of US $\$ 430$ per QALY gained, was quite cost effective compared with no therapy. A sensitivity analysis of the model showed that the results were quite robust; changes in the various parameters of the model had small effects on the results and did not affect the conclusions.

Kim et al (31), using similar techniques but a slightly different model of disease progression, studied CHC patients treated with IFN for both six and 12 months. The authors concluded that, compared with no therapy, therapy of either duration was cost effective, with a cost per QALY gained of US $\$ 2,800$ and US $\$ 3,700$ for six- and 12-month therapy, respectively. Although 12 months of therapy has the higher cost per QALY, the incremental difference between the two durations indicates that longer term therapy, at a cost of US $\$ 5,400$ per QALY, is more cost effective because the additional cost of therapy is more than outweighed by the improved response rate and better outcomes.

One study of consensus IFN, using trial data on SVR rates and similar modelling methods (32), concluded that initial therapy with consensus IFN, with a cost per QALY less than zero, is cost effective and may even be cost saving. Furthermore, this therapy was cost effective, not just for younger patients, but also for those up to age 60 years (32).

IFN therapy for $\mathrm{CHC}$ and its cost have been considered in other studies from the United States (33-36), Canada (37), Australia (38), France (39), Italy (40) and the United Kingdom $(41,42)$. In each case the conclusion has been the same: compared with no therapy, IFN therapy is cost effective (Table 4).

A few studies have considered the economic consequences of strategies that focus treatment on subsets of patients with $\mathrm{CHC}(43-45)$. These researchers considered selecting patients for treatment based on criteria including viral genotype, viral load and histological characteristics at baseline. The conclusions were, first, that routine baseline liver biopsy was not justified from a strictly cost effectiveness perspective and, second, that strategies targetting subsets were more cost effective than treatment of all patients. However, baseline hepatic histopathology provides patients and referring physicians with important prognostic information that cannot be obtained in other ways. Also, in about 20\% to $30 \%$ of patients, baseline hepatic histopathology shows the presence of cirrhosis (when present), which often otherwise would not have been expected. Most experienced hepatologists recommend closer follow-up of patients with cirrhosis, especially to detect and treat large gastroesophageal varices before they bleed, and to detect hepatocellular carcinoma at an early stage when percutaneous or resectional therapy offers a hope for cure and when patients may still be candidates for orthotopic liver transplantation. In addition, strategies that target 'favourable' subsets of patients for therapy may unfairly exclude potential sustained responders from receiving potentially beneficial therapy. 
Retreatment: Recent clinical trial results (50) have heightened interest in analyzing the economics of retreating patients who did not achieve a SVR with initial therapy. Based on these trial data, McHutchison et al (46) found that retreatment with consensus IFN was cost effective. These results held for both relapsers and patients who failed to have a complete biochemical or virological response to initial therapy. In fact, retreatment of relapsers proved to be cost saving, that is, therapy cost was more than offset by the predicted cost savings from reduced future health resource use. Finally, as was the case with initial therapy, longer duration therapy (48 weeks) was more cost effective than short term therapy (24 weeks).

Several recent studies (thus far presented only in abstract form) have examined the cost effectiveness of combination IFN and ribavirin therapy, and all showed that retreatment was cost effective (47-49). Similar to the results of the study of consensus IFN, retreating relapsers with combination therapy was cost saving $(47,48)$, and, based on simulated data, retreating patients who initially failed to respond to treatment was cost effective (49).

In summary, it appears that IFN therapy (with or without ribavirin) is cost effective for patients with $\mathrm{CHC}$. Targeting specific subgroups of patients may increase cost effectiveness but will exclude therapy for some who would show a durable response. For patients who fail to achieve a sustained response to initial therapy, retreatment is economically justified, particularly in those who have complete end-oftreatment responses but who relapse thereafter. Finally, for both initial therapy and retreatment, the benefits of therapy for 48 weeks more than justify the increased costs over 24week therapy.

\section{SUGGESTIONS FOR FUTURE RESEARCH}

Initial research studies raise as many new questions as they provide answers to old ones. Among the still unresolved questions are the following.

Results show clearly that HRQOL is significantly decreased in $\mathrm{CHC}$ patients. However, it is not known why. Are the symptoms somehow due to viruses actually invading nerves, muscles, joints or other tissues? Or, are symptoms chiefly due to changes in cytokines caused by the chronic infection? Can such effects be blocked with specific monoclonal antibodies or receptor antagonists? Will such therapies not only improve HRQOL, but also permit the use of higher doses of IFN or other toxic drugs, thus improving rates of SVR?

Is there benefit to HRQOL even if patients relapse when treatment is stopped? What if such patients are retreated for several years or for an indefinite period? Will such treatment not only prevent development of cirrhosis, hepatic decompensation and hepatocellular carcinoma, but also improve HRQOL over the long term?
What happens to HRQOL during therapy? This question has been addressed thus far in only one small study (Hunt et al [24]), and there seemed surprisingly few significant decreases, particularly when one considers the numerous adverse effects of IFN. Does this suggest a rough balancing of amelioration in symptoms due to viral killing with exacerbation due to IFN?

What are the effects of combination therapy with ribavirin plus IFN, or of other new therapies such as PEGylated IFN, interleukin-10, protease inhibitors or RNA polymerase inhibitors? We expect that other tolerable curative therapy will have effects similar to those of IFN. Indeed, therapies with fewer adverse effects will probably yield even better results.

What is the interplay between HRQOL and cost-economic benefit analyses? Suppose some new, very expensive, but better tolerated therapies than IFN plus ribavirin show promise? How will improvements in HRQOL be balanced against costs? Who will decide who can be treated and for how long? How dependent will answers to these questions be on the cultural contexts in which they are asked?

Is HRQOL worse for patients with $\mathrm{CHC}$ and decompensated cirrhosis than for those with compensated cirrhosis or no cirrhosis? We think so, but have no evidence for it.

Some analysts have evaluated the cost effectiveness of treating subsets of patients based on viral genotype and/or serum viral titre at baseline. In the analyses, they assumed that these factors did not affect anything except the treatment efficacy. However, if there are differences among subgroups in either disease progression or outcome, then the economic results are no longer valid. In fact, the results may be reversed that it could be more cost effective to treat the very subgroups they exclude. Thus, it is important to determine the natural history and outcomes with some degree of confidence before forming conclusions about the economics of treatment about subgroups.

What are the effects of other types of chronic viral hepatitis, especially chronic hepatitis B, compared with the effects of CHC? This has been assessed thus far in only 30 patients in a study done in London. United Kingdom. Does CHC produce more severe systemic side effects for any given degree of liver injury? Does this imply a greater psychological-emotional effect of $\mathrm{HCV}$ than HBV infection? Are there other viruses of similar importance?

What will results of HRQOL assessments be among patients in other countries or cultures? How will results in other countries compare with those in the United States, Canada and the United Kingdom (the only countries thus far studied)? 
ACKNOWLEDGEMENTS: Supported by Amgen, Inc (Thousand Oaks, California), and by a grant and contract from the $\mathrm{Na}$ tional Institutes of Health (NIH) (RO-1-DK38825 and NO-1-DK9-2326to Herbert L Bonkovsky). The opinions expressed herein are those of the authors. They do not necessarily reflect the official views of Amgen, Inc, the United States Public Health Service or the NIH. We thank Jane Blackwood for typing the manuscript.
25. Foster GR, Boldin RD, Thomas HC. Chronic hepatitis $\mathrm{C}$ virus infection causes a significant reduction in quality of life in the absence of cirrhosis. Hepatology 1998;27:209-12.

26. Bonkovsky HL, Woolley JM. Reduction of health-related quality of life in chronic hepatitis $\mathrm{C}$ and improvement with interferon therapy. Hepatology 1999;29:264-70.

27. Tong MJ, Reddy KR, Lee WM, et al. Treatment of chronic hepatitis C with consensus interferon: A multicenter, randomized, controlled trial. Hepatology 1997;26:747-54.

28. Marcellin P, Boyer N, Gervais A, et al. Long-term histologic improvement and loss of detectable intrahepatic HCV RNA in patients with chronic hepatitis $C$ and sustained response to interferon- therapy. Ann Intern Med 1997,127:875-81.

29. Bennett WG, Pauker SG, Davis GL, Wong JB. Modeling therapeutic benefit in the midst of uncertainty: therapy for hepatitis C. Dig Dis Sci 1996:41:56S-62S.

30. Bennett WG, Inoue Y, Beck JR, Wong JB, Pauker SG, Davis GL. Estimates of the cost-effectiveness of a single course of interferon in patients with histologically mild chronic hepatitis C. Ann Intern Med 1997;127:855-65.

31. Kim WR, Poterucha JJ, Hermans JE, et al. Cost-effectiveness of 6 and 12 months of interferon-alpha therapy for chronic hepatitis C. Ann Intern Med 1997;127:866-74.

32. McHutchison JG, Woolley JM, Nyberg LM. Cost effectiveness of consensus interferon therapy for chronic HCV infection. Hepatology 1997;26:421A. (Abst)

33. Bennett WG, Inoue Y, Beck JR, Pauker SG, Davis GL. Justification of a single 6-month course of interferon (IFN) for histologically mild chronic hepatitis C. Hepatology 1995;22:290A. (Abst)

34. Kim WR, Poterucha JJ, Gross JB, Dickson ER, Evans RW. Cost-effectiveness of 12 -months of interferon treatment for chronic hepatitis C. Hepatology 1996;26:A1233. (Abst)

35. Davis GL, Beck JR, Farrell G, Poynard T. Prolonged course versus 6-months of interferon alpha or no treatment in patients with histologically mild chronic hepatitis C: a decision analysis. Gastroenterology 1997;112:A1252. (Abst)

36. Kareemi M, Peltekian KM. Cost-effectiveness of interferon treatment for chronic hepatitis C. Hepatology 1996;26:597A. (Abst)

37. Heathcote J, Lee S, Pare P, Haider S, Beck B. Cost-effectiveness evaluation of a single course of interferon-alpha $2 \mathrm{~B}$ in patients with histologically mild chronic hepatitis C: a Canadian analysis. Hepatology 1998;28:377A. (Abst)

38. Shiell A, Briggs A, Farrell GC. The cost effectiveness of alpha interferon in the treatment of chronic hepatitis C. Med J Aust 1994;160:268-72.

39. Joliot E, Vanlemmens C, Kerleau M, et al. Analyse cout-efficacite du traitement de l'hepatite chronique C. Gastroenterol Clin Biol 1996:20:958-67.

40. Munari LM, Piciotto C. Recombinant interferon 2b therapy of chronic hepatitis C in Italy: an economic analysis. Forum Trends Exp Clin Med 1996;6:347-53.

41. Garcia de Ancos JL, Roberts JA, Dusheiko GM. An economic evaluation of the costs of interferon treatment of chronic active hepatitis due to hepatitis B or C virus. J Hepatol 1990;11:S11-8.

42. Dusheiko GM, Roberts JA. Treatment of chronic type B and C hepatitis with interferon alpha: an economic appraisal. Hepatology 1995;22:1863-82.

43. Younossi ZM, McHutchison JG. Interferon treatment of chronic HCV infection: an economic analysis of different strategies. Gastroenterology 1996;110:A47. (Abst)

44. Bennett WG, Wong JB, Koff RS, Ishida H, Beck JR, Pauker SG. What is the optimal pretreatment evaluation of chronic hepatitis $\mathrm{C}$ ? Hepatology 1996;25:1029A. (Abst)

45. Wong JB, Bennett WG, Koff RS, Pauker SG. Pretreatment evaluation of chronic hepatitis C. JAMA 1998;280:2088-93.

46. McHutchison JG, Woolley JM, Nyberg LM. Cost effectiveness of retreatment with consensus interferon for chronic hepatitis C. Hepatology 1997;26:421A. (Abst)

47. Wong JB, Davis GL, Pauker SG. Cost-effectiveness of ribavirin/interferon alpha-2B after interferon relapse in chronic hepatitis C. Hepatology 1998;28:591A. (Abst)

48. Kim WR, Poterucha JJ, Dickson ER, Gross JB: Economic analysis of interferon/ribavirin treatment in patients with chronic hepatitis $\mathrm{C}$ who relapse following initial interferon therapy. Gastroenterology 1998;114:A1274. (Abst)

49. Kim WR, Poterucha JJ, Dickson ER, Gross JB. Cost-effectiveness of interferon/ribavirin treatment among nonresponders to initial interferon therapy for chronic hepatitis C. Hepatology 1998;28:231A. (Abst) 
Bonkovsky and Woolley

50. Heathcote EJ, Keeffe EB, Lee SS, et al. Re-treatment of chronic hepatitis

C with consensus interferon. Hepatology 1998;27:1136-43.

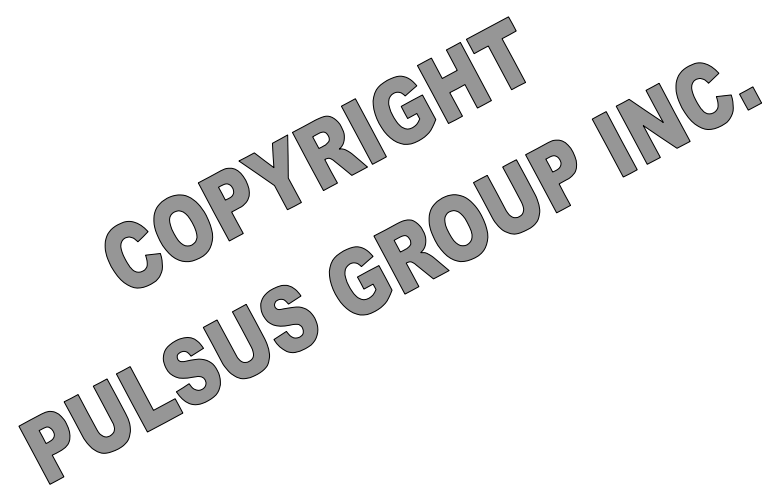




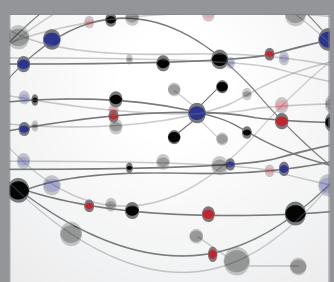

The Scientific World Journal
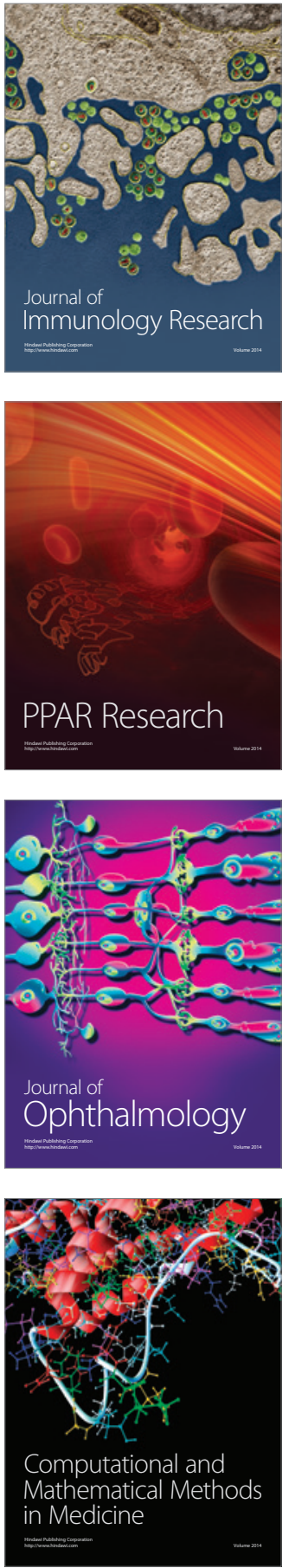

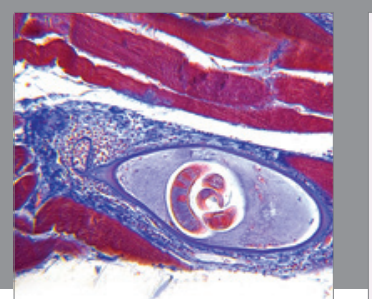

Gastroenterology Research and Practice

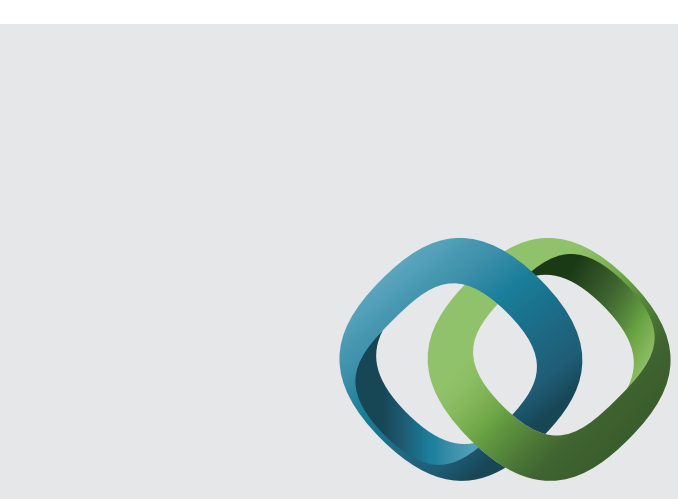

\section{Hindawi}

Submit your manuscripts at

http://www.hindawi.com
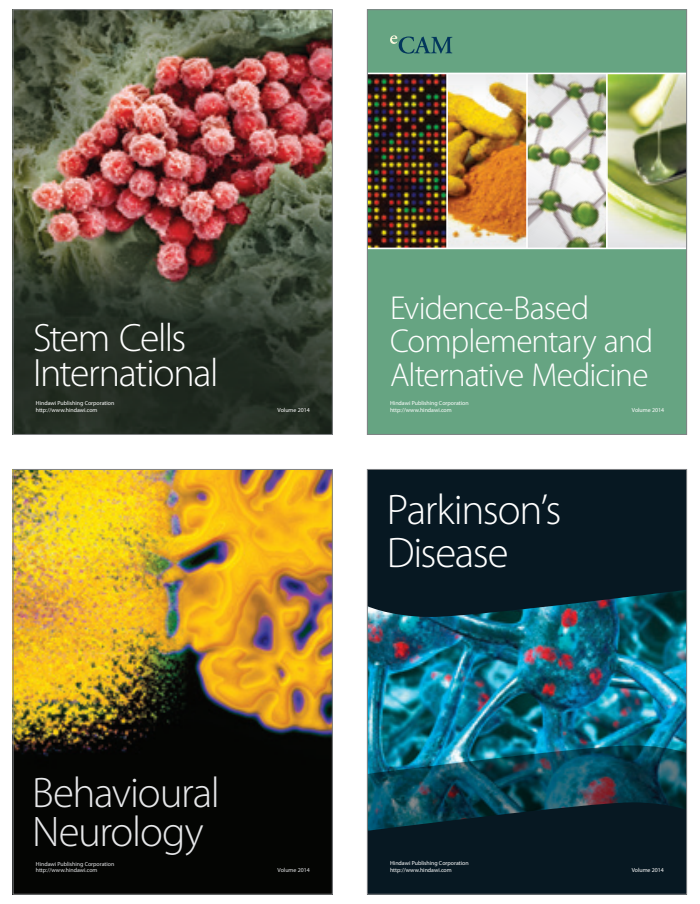
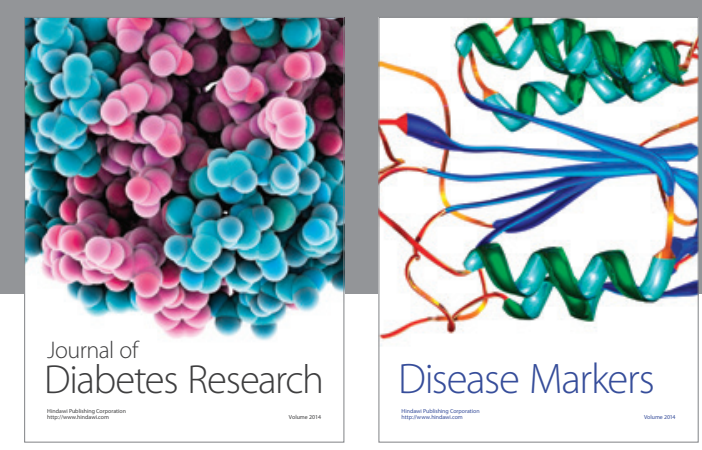

Disease Markers
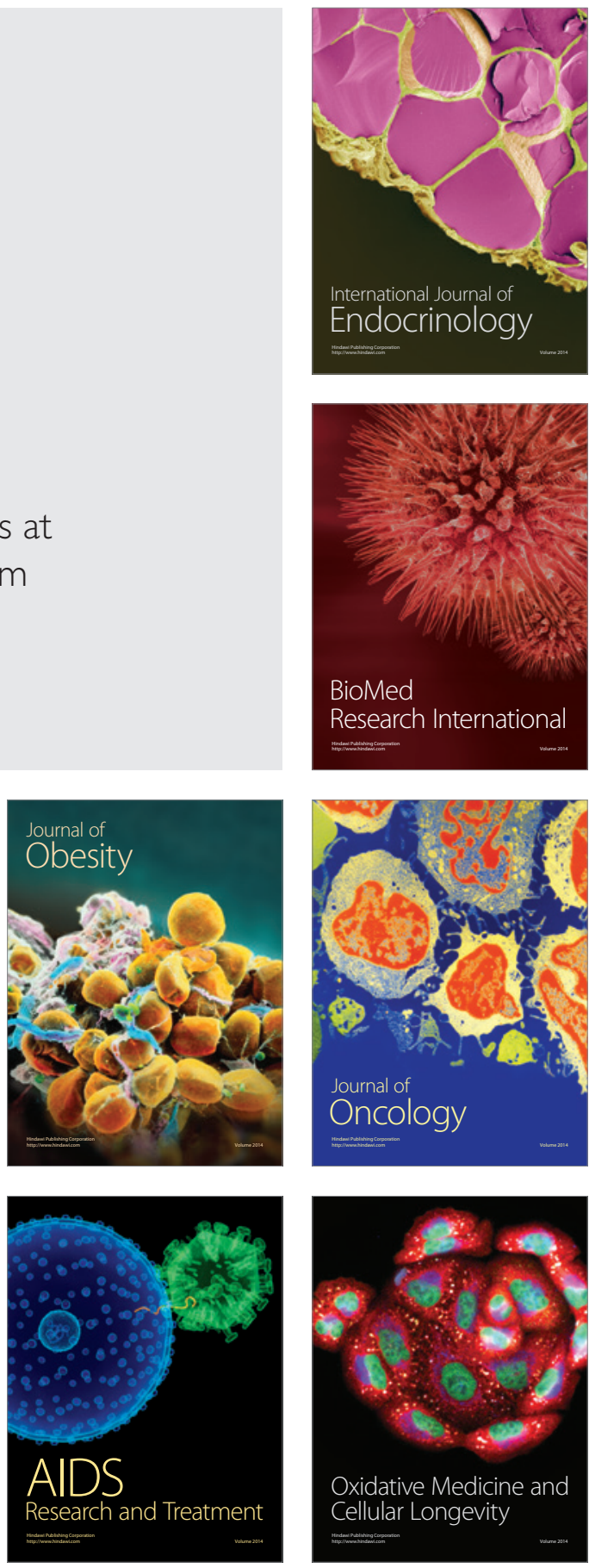